\title{
Microstructural evolution during isothermal annealing of a cold-rolled Al-Mn-Fe-Si alloy with different microchemistry states
}

\author{
Ke Huang ${ }^{1, a}$, Yanjun $\mathrm{Li}^{1, \mathrm{~b}}$ and Knut Marthinsen ${ }^{1, \mathrm{c}}$ \\ ${ }^{1}$ Norwegian University of Science and Technology, N-7491 Trondheim, Norway \\ ake.huang@ntnu.no, byanjun.li@ntnu.no, ${ }^{\mathrm{b}}$ knut.marthinsen@ntnu.no
}

Keywords: Aluminium alloys, recrystallization, microchemistry, microstructural evolution, particles, EBSD

\begin{abstract}
In this paper, investigation of the softening behaviour of a supersaturated Al-Mn-Fe-Si alloy during annealing after cold rolling has been carried out. Two different homogenization conditions were considered, of which one gives a condition of a large amount of small pre-existing dispersoids, i.e. providing a significant static Zener drag, while the other gives a condition where both concurrent precipitation and dispersoid drag effects are limited. The homogenized samples with different microchemistry states were then cold-rolled to different strains before subsequent annealing at $300^{\circ} \mathrm{C}$. The softening and concurrent precipitation behaviours have been monitored by hardness and electrical conductivity measurements respectively, and the microstructural evolution has been characterized by EBSD. It is clearly demonstrated that the actual microchemistry state, i.e. amount of solutes and second-phase particle structures as determined by the homogenization procedure strongly influence the softening behaviour where a fine dispersion of pre-existing dispersoids together with concurrent precipitation slow down the recrystallization kinetics considerably and give a very coarse and elongated grain structure.
\end{abstract}

\section{Introduction}

AA3xxx alloys, which contain large Al-Mn-Fe-Si constituent particles and/or finely dispersed particles (dispersoids), are widely used in automobile industry, architecture and packaging industry. It is widely accepted that second-phase particles are of the utmost importance for the recrystallization of alloys containing such particles [1-4]. In general, large particles can act as nucleation sites to promote nucleation while fine dispersoids can inhibit nucleation process by pinning boundaries at the initial stage of the recrystallization process [5]. The microchemistry state of the alloys, i.e. amount of solutes and second-phase particle structures, determined by the chemical composition and homogenization procedures of the alloys is thus an important aspect in studying the softening behaviour of deformed AA3xxx alloys. The softening behaviour of deformed AA3xxx aluminium alloys during isothermal heat treatments, in terms of recrystallization kinetics, final microstructure and texture, have been extensively investigated in several papers [6-8], some of which already focused on the interactions between dispersoids/precipitation. Less focus, however, has been paid to the temporal microstructure evolution during annealing of AA3xxx alloys [9].

In this paper, the effect of microchemistry states on the softening behaviour of cold-rolled $\mathrm{Al}-\mathrm{Mn}-\mathrm{Fe}-\mathrm{Si}$ alloys is analysed during isothermal annealing treatments at $300{ }^{\circ} \mathrm{C}$. Different microchemistry states were obtained by varying the homogenization conditions. The softening behaviours of the deformed samples with different microchemistry states have been monitored by hardness and electrical conductivity measurements, and the microstructural evolution has been characterized by EBSD.

\section{Experimental details}

Alloy conditions and annealing treatment. For the current study, the investigated materials were commercial DC-cast AA3xxx extrusion billets, supplied by Hydro Aluminium. The as-received 
materials were in as-cast state, with the chemical compositions listed in Table1. The cast materials have an equiaxed grain structure with an average grain size of $\sim 140 \mu \mathrm{m}$, and constituent particles are mostly decorated in the interdendritic regions and grain boundaries [10].

Table 1 Chemical composition of the AA 3xxx model alloys, in wt. \%

\begin{tabular}{lcccc}
\hline Alloy & $\mathrm{Si}$ & $\mathrm{Fe}$ & $\mathrm{Mn}$ & Others \\
& & & & \\
\hline $\mathrm{C} 1$ & 0.152 & 0.530 & 0.390 & $<0.01$ \\
\hline
\end{tabular}

The received material (denoted as $\mathrm{C} 1$ ) was subsequently homogenized at two different conditions to get different microchemistries in terms of solutes and second-phase particles. The homogenization treatments were conducted in an air circulation furnace with a temperature accuracy of $\pm 2 \mathrm{~K}$, starting from room temperature (about $20{ }^{\circ} \mathrm{C}$ ). One set of the samples were heated at $50^{\circ} \mathrm{C} / \mathrm{h}$ to $450{ }^{\circ} \mathrm{C}$ and kept for 4 hours, refereed as $\mathrm{C} 1-2$. Another set of the samples were subjected to a two-stage homogenization treatment. First, the samples were heated at $50^{\circ} \mathrm{C} / \mathrm{h}$ to $600{ }^{\circ} \mathrm{C}$ for 4 hours, then these samples were cooled at $25^{\circ} \mathrm{C} / \mathrm{h}$ to $500^{\circ} \mathrm{C}$ where they were kept for another 4 hours, giving the $\mathrm{C} 1-3$ condition. Materials were water quenched to room temperature at the end of the homogenization procedure to freeze the state of supersaturation/precipitation state. The variant homogenized at the lower temperature, i.e. C1-2, has obviously more but finer dispersoids than its counterpart C1-3, as illustrated in Fig.1, noticing that the magnification of the two graphs is different. The sizes of the constituent particles for $\mathrm{C} 1-2$ and $\mathrm{C} 1-3$ are $0.96 \mu \mathrm{m}$ and $1.1 \mu \mathrm{m}$, respectively. It turned out that the C1-2 variant has higher solid solution level of Mn (0.16 wt.\%) than C1-3 (0.11 wt.\%), which provides a larger potential for concurrent precipitation, for which more details can be found in reference [8].
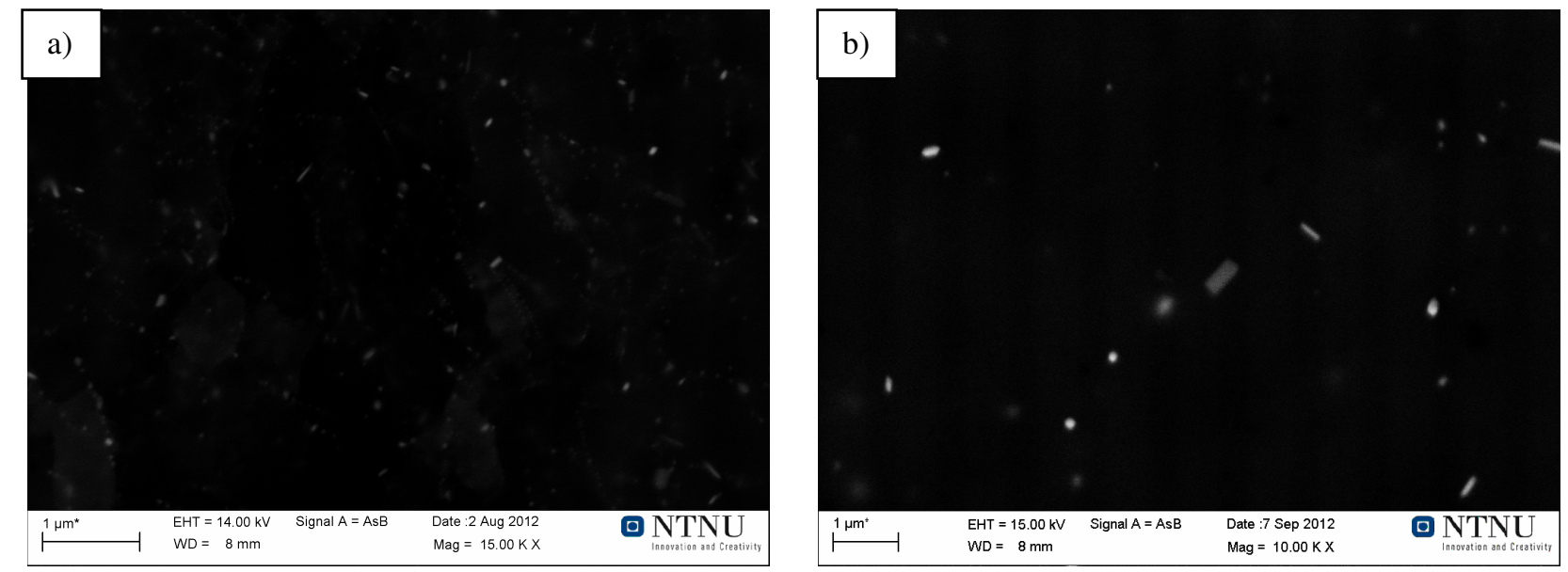

Fig.1 BSE-SEM images of the dispersoids for the two homogenized states.
a) $\mathrm{C} 1-2$;
b) $\mathrm{C} 1-3$

The homogenized materials were then cold rolled to three different strains $\varepsilon=0.7,1.6$ and 3.0. The rolled sheets were then isothermally back-annealed in a pre-heated salt bath at $300{ }^{\circ} \mathrm{C}$ and with different holding times in the range of $5-10^{5} \mathrm{~s}$, followed by quick water quenching.

Microstructure characterization. The softening and precipitation behaviours during annealing were followed by Vickers hardness (VHN) and electrical conductivity (EC) measurements performed on the RD-TD plane of sheets. Each reported value was obtained by averaging eight measurements. EC value was measured by a Sigmascope EX 8 at room temperature of about $293 \mathrm{~K}\left(20{ }^{\circ} \mathrm{C}\right)$. Metallographic examinations of constituent particles and dispersoids were performed by backscatter electron channelling contrast imaging in a Zeiss Ultra 55 field emission gun scanning electron microscope (FEG-SEM). Images were captured electronically and analysed using standard image 
analysis software. Characteristic size parameters of constituent particles, equivalent diameter $d$ and number density were measured by the image analysis software Image-J. For the hardness measurements, a load of $1 \mathrm{Kg}$, a loading time of $15 \mathrm{~s}$ and a loading speed of $100 \mu \mathrm{ms}^{-1}$ were used.

The microstructures of the sheets were measured by means of EBSD (Electron backscattered diffraction) on a Zeiss Supra/Ultra 55 SEM equipped with TSL software. The EBSD maps were obtained with step size of $0.5 \sim 1 \mu \mathrm{m}$. For all of the micrographs presented below in this paper, the horizontal direction corresponds to rolling direction (RD) while the vertical direction is the normal direction (ND). The grain size was measured as the equivalent area diameter in the RD-ND cross section.

\section{Results and Discussions}

Recrystallization and concurrent precipitation behaviours. After cold rolling to different strains in the range $0.7-3.0$, the two variants were isothermally annealed in salt bath at $300^{\circ} \mathrm{C}$ and interrupted at different times until $10^{5} \mathrm{~s}$, their evolution in terms of hardness and EC values were analysed and presented in Figs. 2 and 3.

From Fig.2, it can be seen that fully recrystallized states were obtained after annealing for $10^{4} \mathrm{~s}$ for the samples of C1-3 deformed to $\varepsilon=1.6$ and $\varepsilon=3.0$, while the sample deformed at $\varepsilon=0.7$ needed a longer annealing time to complete recrystallization. The softening behaviours of the samples deformed to $\varepsilon=1.6$ and $\varepsilon=3.0$ are quite similar (Fig.2a). On the other hand, relatively small increase of EC was observed for all the three cases of C1-3. This is expected since the C1-3 samples have a weaker potential for concurrent precipitation and have limited number of pre-existing dispersoids. A higher increase of EC was found for the samples with the largest deformation. The increase in EC was $1.9,1.5,1.2 \mathrm{~m} / \Omega \mathrm{mm}^{2}$ for the samples deformed at $\varepsilon=3.0, \varepsilon=1.6, \varepsilon=0.7$, respectively.
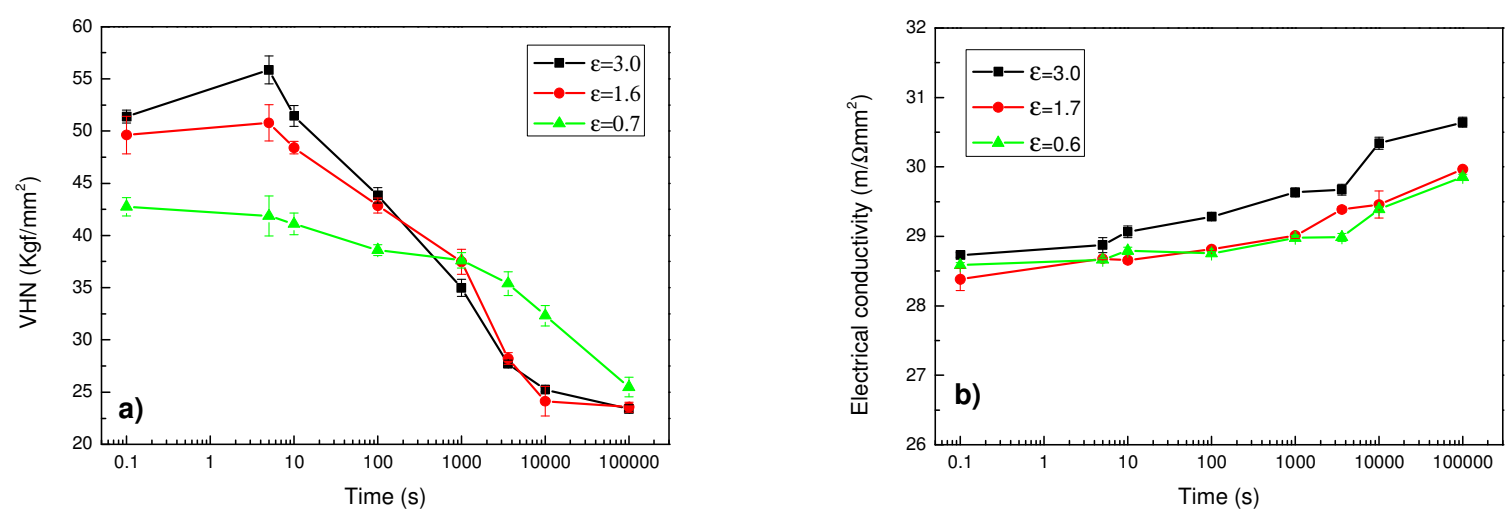

Fig. 2 The variations of hardness and $\mathrm{EC}$ with time during isothermal annealing of $\mathrm{C} 1-3$ at $300^{\circ} \mathrm{C}$, after cold rolled to different strains.

a) Hardness; b) Electrical conductivity

For the C1-2 samples, which have large amounts of fine pre-existing dispersoids and a higher potential for concurrent precipitation, fully recrystallized state was still not reached after annealing for $10^{5} \mathrm{~s}$ even for the case deformed at $\varepsilon=3.0$ (Fig.3a). The softening behaviour was similar for the cases deformed at $\varepsilon=1.6$ and $\varepsilon=0.7$, all three cases were dominated by recovery. The slow recrystallization kinetics should be ascribed to the second-phase particles including the pre-existing dispersoids and concurrently precipitated ones which suppress nucleation and retard grain boundary migration. For the concurrent precipitation behaviour, which is estimated by the EC evolution, a relatively larger increase was observed for all the three cases as compared to their counterparts of C1-3 samples (Fig.3b). The increase in EC values are 2.9, 2.0, $1.5 \mathrm{~m} / \Omega \mathrm{mm}^{2}$ for the samples deformed at $\varepsilon=3.0, \varepsilon=1.6, \varepsilon=0.7$, respectively. 

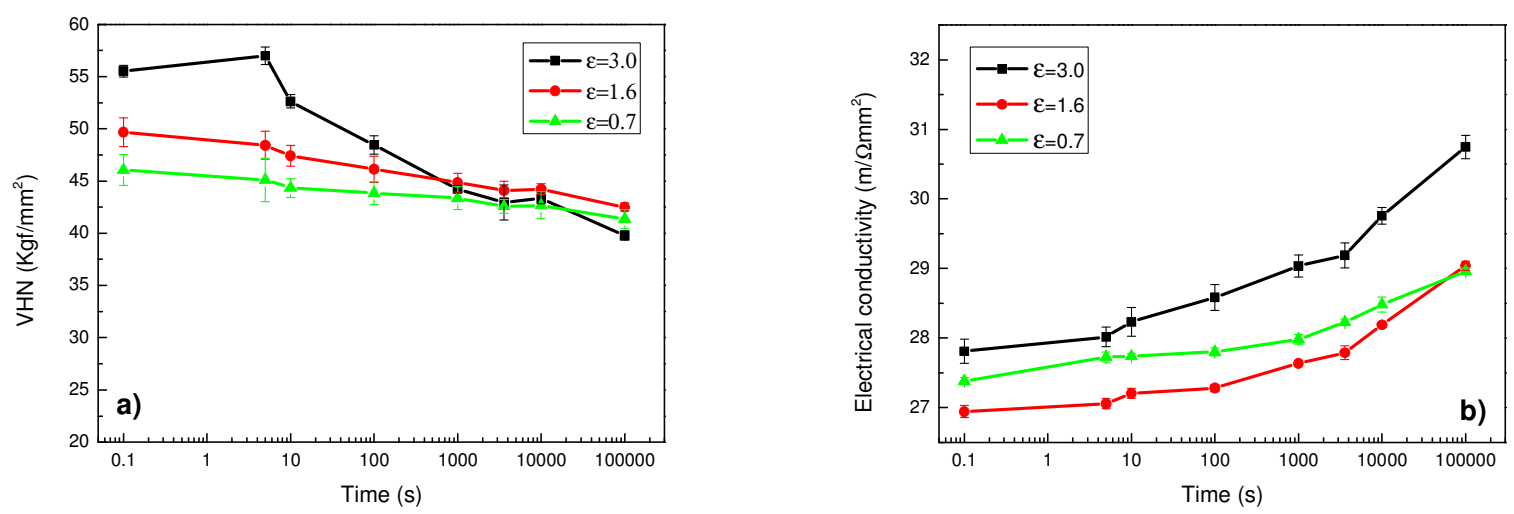

Fig. 3 The variations of hardness and $\mathrm{EC}$ with time during isothermal annealing of $\mathrm{C} 1-2$ at $300^{\circ} \mathrm{C}$, after cold rolled to different strains.

a) Hardness; b) Electrical conductivity

Microstructure evolution. The effect of microchemistry state on the microstructure evolution has also been investigated. Since recrystallization is very slow for C1-2 samples (see Fig.3a), only the microstructural evolution of the samples with largest deformation $(\varepsilon=3)$ is analysed. It can be clearly seen from Fig.4 that the pre-existing dispersoids are more or less randomly distributed.
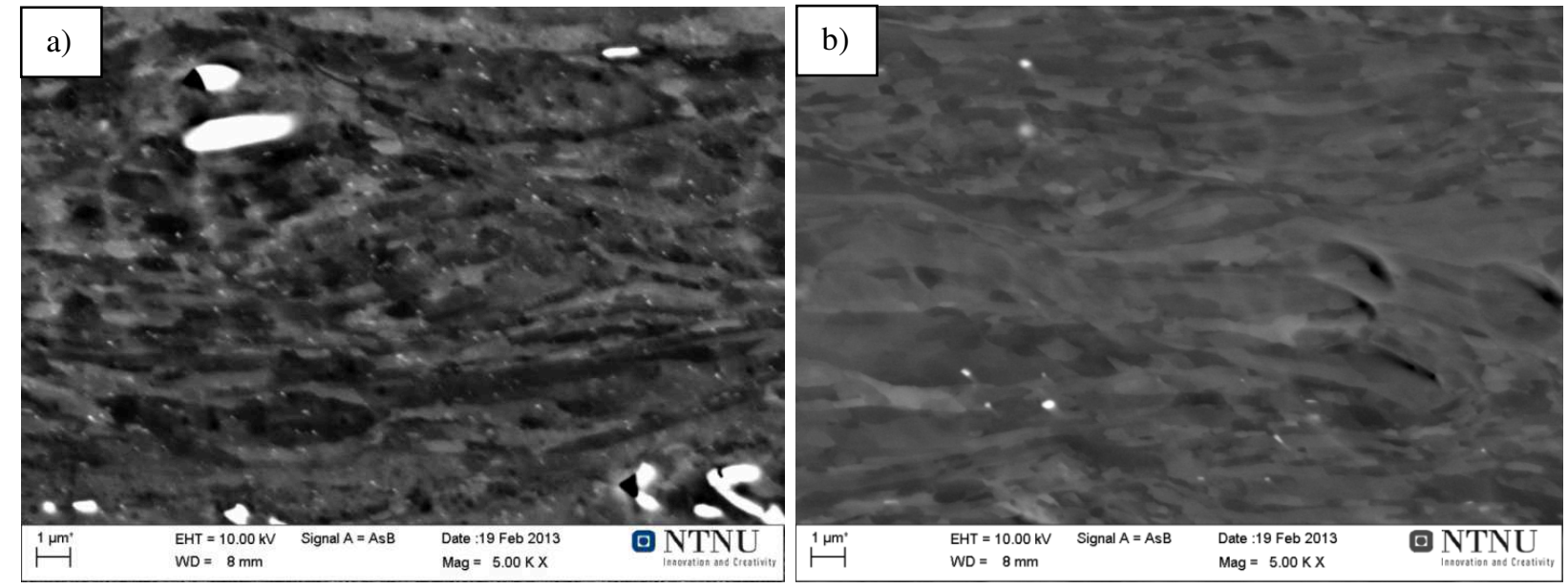

Fig.4 BSE-SEM images of the dispersoids for the two homogenized states after deformation to 3.0.

$$
\text { a) } \mathrm{C} 1-2 \text {; } \quad \text { b) } \mathrm{C} 1-3
$$

The gradual progress of recrystallization during isothermal annealing at $300^{\circ} \mathrm{C}$ of $\mathrm{C} 1-3$ samples after strain of $\varepsilon=3$ is shown in Fig.5. A large number of recrystallized grains, with equiaxed shape, are already present after a short annealing time of 500s. In general, the recrystallized grains are mainly randomly distributed, rather than in bands or cluster. As these recrystallized grains are growing, their close to equiaxed shape further confirms that the recrystallization process is only weakly affected by the pre-existing dispersoids and concurrently precipitated ones, both of which are limited in number. Some of the recrystallized grains are already impinged by others after annealing for 1000s. The growth of recrystallized grains is accompanied by a continuous formation of new nuclei at longer annealing times, as observed in all micrographs at larger annealing times ( $>2000 \mathrm{~s}$ ), which finally leads to a bimodal grain structure with both finer grains that have been recently nucleated and larger grains that formed earlier. 

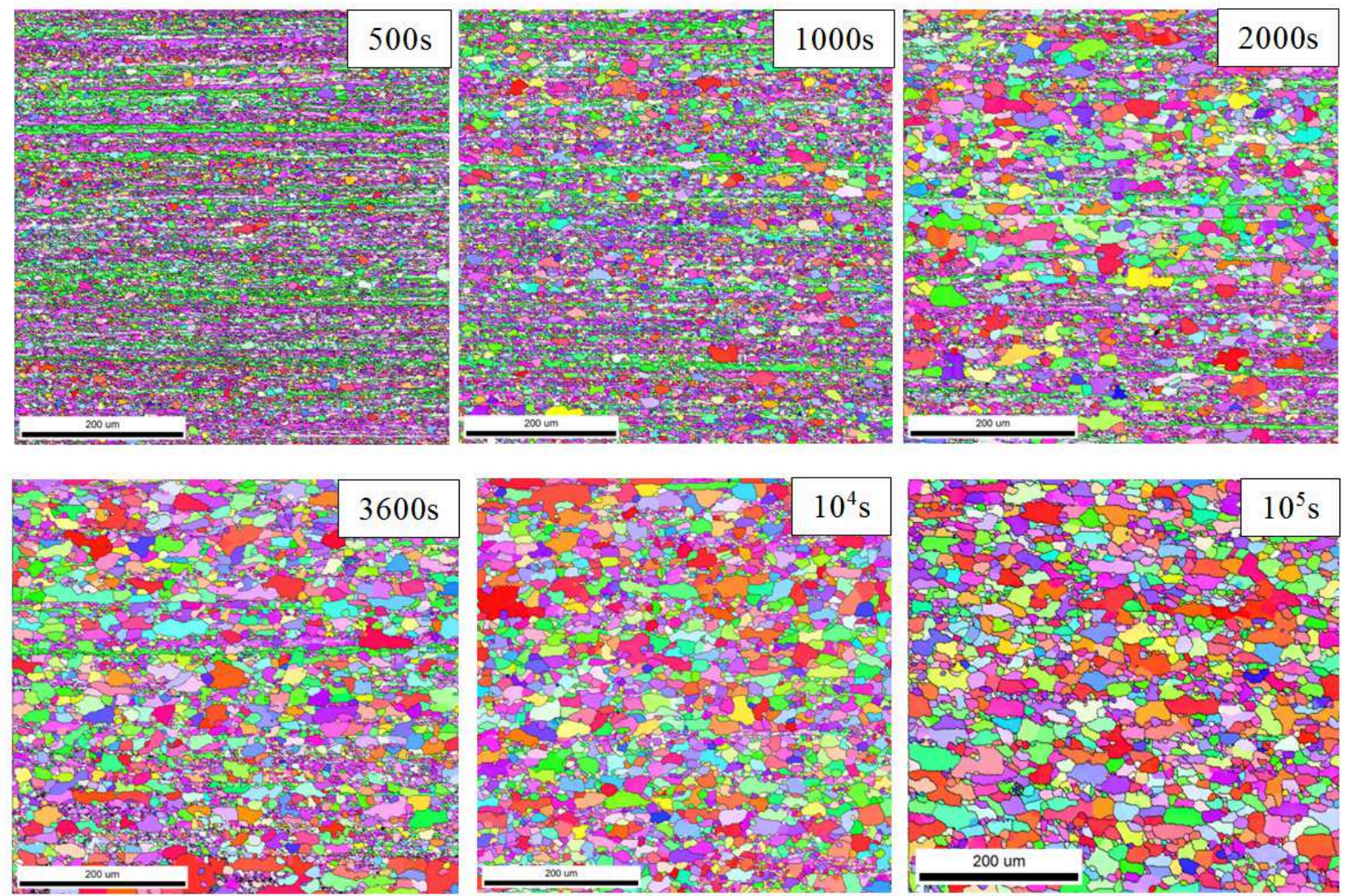

Fig.5 EBSD micrographs showing the microstructural evolution of C1-3 during isothermal annealing at $300^{\circ} \mathrm{C}$ after cold rolling to 3.0

For the C1-2 samples, which have more pre-existing dispersoids (see Fig.4) and stronger concurrent precipitation (cf. evolution in EC; $1.0 \mathrm{~m} / \Omega \mathrm{mm}^{2}$ more (Fig. 3b)) than that of C1-3 samples, recrystallization kinetics is much slower even for the samples deformed at $\varepsilon=3$. Recrystallization in this case was strongly retarded by both pre-existing dispersoids and concurrent precipitation. After annealing for 3600s, recrystallization is completed for C1-3 sample as shown in Fig. 5, while only few small recrystallized grains are visible for C1-2, as illustrated in Fig.6. Even the much longer annealing time of $10^{5} \mathrm{~s}$ does not lead to a fully recrystallized state, only a few coarse elongated grains are present, leaving the large part of the material non-recrystallized. The elongated grains should mainly be ascribed to concurrent precipitation, which takes place on the high angle grain boundaries [11] and exerts an increased dragging force along the ND direction. The strongly suppressed nucleation from both pre-existing dispersoids and concurrent precipitation also contributed to this grain structure.
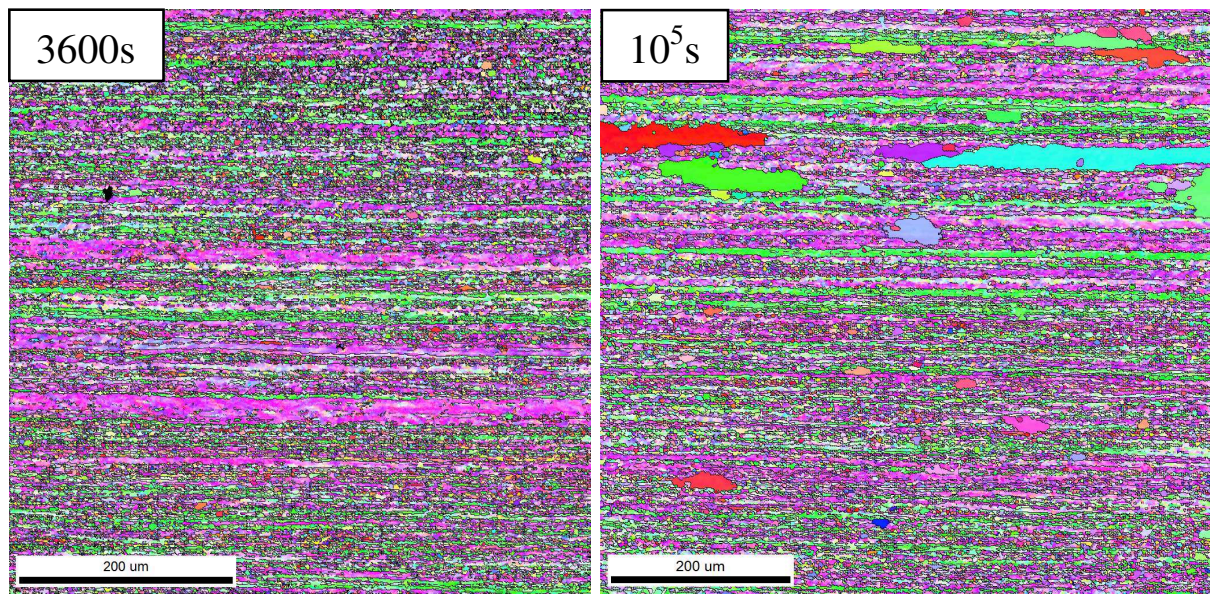

Fig.6 EBSD micrographs showing the microstructural evolution of $\mathrm{C} 1-2$ during isothermal annealing at $300^{\circ} \mathrm{C}$ after cold rolling to 3.0 
From the above analyses, different microchemistry states have proved to significantly affect the softening and concurrent precipitation behaviours using two variants obtained after different homogenizations of the same alloy. It is hard to conclude, however, how the pre-existing dispersoids and concurrent precipitation slow down the recrystallization kinetics for C1-2 quantitatively. The fact that concurrent precipitation evolves with time adds difficulties to the analysis. Further investigations which can separate the effects of pre-existing dispersoids and concurrent precipitation should be done to clarify this. Numerical models [e.g.12] which take into account of the interaction between recrystallization and second-phase particles should be helpful to obtain a better understanding of this complicated interaction.

\section{Summary}

The softening behaviour of Al-Mn-Fe-Si alloys during annealing after cold rolling to different strains has been investigated. The effect of microchemistry in terms of $\mathrm{Mn}$ in solid solution and dispersoids, introduced prior to cold rolling through different homogenization treatments, on microstructural evolution is analysed during subsequent isothermal heating experiments. It is clearly demonstrated that the actual microchemistry state, i.e. amount of solute and dispersoid structures as determined by the homogenization procedure strongly influence the softening behaviour where both a fine dispersion of pre-existing dispersoids as well as significant concurrent precipitation slow down the recrystallization kinetics considerably and give a very coarse and elongated grain structure.

Acknowledgement: Financial support by the Research Council of Norway (Project No: 193179/I40) and the industrial partners, Hydro Aluminium and Sapa Technology is gratefully acknowledged. NTNU, through the "Strategic Area Materials" is also gratefully acknowledged for financial support to postdoc Ke Huang.

\section{References}

[1] F.J. Humphreys, Acta Metall. 25 (1977) 1323-1344.

[2] R.D. Doherty, D.A. Hughes, F.J. Humphreys, J.J. Jonas, D. Juul Jensen, M.E. Kassner et al., Mater. Sci. Eng. A 238 (1997) 219-274.

[3] F.J. Humphreys, Scripta Mater. 43 (2000) 591-596.

[4] O. Daaland, E. Nes, Acta Mater. 44 (1996) 1413-1435.

[5] N. Hansen, B. Bay, Acta Metall. 29 (1981) 65-77.

[6] W.C.Liu, J.G.Morris, Metall. Mater.Trans. A 36A (2004) 2005-2829

[7] S.Tangen, K.Sjølstad, T.Furu, E.Nes, Metall. Mater.Trans. A 41A (2010) 2970-2983

[8] K.Huang, N.Wang, Y.J.Li, K.Marthinsen, Mater. Sci.Eng. A 601 (2014) 86-96

[9] K.Huang, Y.J.Li, K.Marthinsen, submitted to Trans.Nonferrous.Met.Soc.China (2014)

[10] K.Huang, Y.J.Li, K.Marthinsen, Mater.Sci.Forum. Thermec 2013. (2014) Accepted

[11] M. Somerday, F.J. Humphreys, Mater. Sci. Technol. 19 (2003) 20-29

[12] E. Hersent, K. Huang, J. Friis, K. Marthinsen, Mater.Sci.Forum.753 (2013) 143-146. 